\title{
Two Cases of Methemoglobinemia Induced by the Exposure to Nitrobenzene and Aniline
}

\author{
Chang Hwan Lee ${ }^{1}$, Soo Hyeon Kim', Do Hyung Kwon ${ }^{1}$, Keun Ho Jang ${ }^{1}$, Yong Hoon Chung ${ }^{2}$ and Jai Dong Moon ${ }^{1 *}$
}

\begin{abstract}
Objective: To report two cases of methemoglobinemia induced by inhaled nitrobenzene and dermally absorbed aniline.

Methods: We have evaluated a 37-year-old male worker exposed to nitrobenzene by inhalation while conducting maintenance job of mononitrobenzene pump and a 25-year-old male worker exposed dermally to aniline while unloading.

Results: The first case is a 37-year-old male exposed to nitrobenzene. His blood methemoglobin concentration level was initially $19.8 \%$, and chest X-ray was normal. After oxygen therapy, the blood methemoglobin concentration level decreased to $2.1 \%$, and the symptoms were alleviated. The second case is a 25 -year-old male exposed dermally to aniline. His chest X-ray was normal, but blood methemoglobin concentration level reached maximally 46.8\%. He was treated with methylene blue due to relatively high blood methemoglobin level. Gradually after the treatment, his methemoglobin concentration level was normalized to $0.8 \%$ and simultaneously symptoms were resolved.

Conclusions: After the thorough exposure investigations and medical evaluations, we have concluded that these cases were methemoglobinemia induced by occupational exposure to nitrobenzene and aniline. We suggest that businesses which handle methemoglobinemia-causing substances control the engineering process strictly, implement periodic screening, and establish emergency patient management system.
\end{abstract}

Keywords: Nitrobenzene, Aniline, Methemoglobinemia

\section{Background}

Methemoglobin (MetHb) is a modified form of normal hemoglobin where $\mathrm{Fe} 2+$ (ferrous ion) is oxidized into Fe3+ (ferric ion). MetHb cannot bind with oxygen, and hence it cannot carry oxygen. The human body can tolerate a very small amount (less than 1\%) of MetHb, but a higher level is likely to cause methemoglobinemia [1-4].

Methemoglobinemia can be both inherited and acquired. Methemoglobinemia is commonly caused by exposure to medical substances, such as benzocaine and dapsone, that oxidize hemoglobin to MetHb; exhaust fumes from internal combustion engines; herbicides and pesticides; and chemicals, such as nitrobenzene and aniline [5-11]. Nitrobenzene and aniline are typical aromatic nitro compounds and aromatic amino compounds that cause methemoglobinemia.

\footnotetext{
* Correspondence: jdmoon@chol.com

'Department of Occupational and Environmental Medicine, Chonnam

National University Hwasun Hospital, Hwasun, Korea

Full list of author information is available at the end of the article
}

Nitrobenzene is mostly used in the synthesis of aniline and in the production of benzidine, quinolone, and azobenzene [12]. Nitrobenzene is a pale yellow liquid, which has an almond-like odor at room temperature. The most common paths of occupational exposure to nitrobenzene are inhalation and absorption through the skin [12-15]. The reduction of nitrobenzene to aniline occurs once nitrobenzene is metabolized within the body, and this process oxidizes the hemoglobin in the blood into MetHb, which then causes methemoglobinemia [1,14].

Aniline is a prototypical aromatic amine in a pale yellow liquid form with an unpleasant odor of rotten fish. It is used in the production of dyes, rubber processing chemicals, and antioxidants [16]. The most common occupational exposure to aniline includes inhalation, oral ingestion, and absorption through the skin. Hydroxylamine compounds, such as phenylhydroxylamine, are known to cause methemoglobinemia when they begin oxidation [17-19]. 
In this paper, we report two cases of methemoglobinemia that occurred in chemical plants following exposure to nitrobenzene and aniline through inhalation and absorption through the skin, as well as a review of the literature related to occupational methemoglobinemia.

\section{Case presentation}

\section{Case 1}

Patient

37-year-old male.

\section{Chief complaint}

Dyspnea, cyanoderma.

Past medical history and/or family history

Nothing significant.

History of cigarette smoking and alcohol consumption Nonsmoker, rarely drinks.

\section{Occupational history}

The patient works in methylene diphenyl diisocyanate (MDI) production (Figure 1). Prior to experiencing symptoms, the patient had been cleaning a suction strainer of a mononitrobenzene pump for six to seven hours. The process of cleaning a suction strainer starts from opening the cover of the strainer, taking out the screen that is inside, removing impurities and foreign substances, and then reassembling the strainer. It is likely that the patient was exposed to mononitrobenzene through inhalation during this process.

\section{History of present illness}

The patient displayed no symptoms while cleaning the suction strainer of the mononitrobenzene pump, but he experienced dyspnea and cyanoderma shortly after he returned home after work. He was immediately taken to the local hospital. As he showed no improvement after emergency treatment, including oxygen inhalation therapy, he was transferred to the emergency room after consulting the Department of Occupational \& Environmental Medicine of an affiliated university hospital in accordance with the emergency patient management guidelines of the workplace.

\section{Physical findings}

At the time of transfer, his blood pressure was 110/ $70 \mathrm{mmHg}$, his pulse rate was 88 beats per minute, his

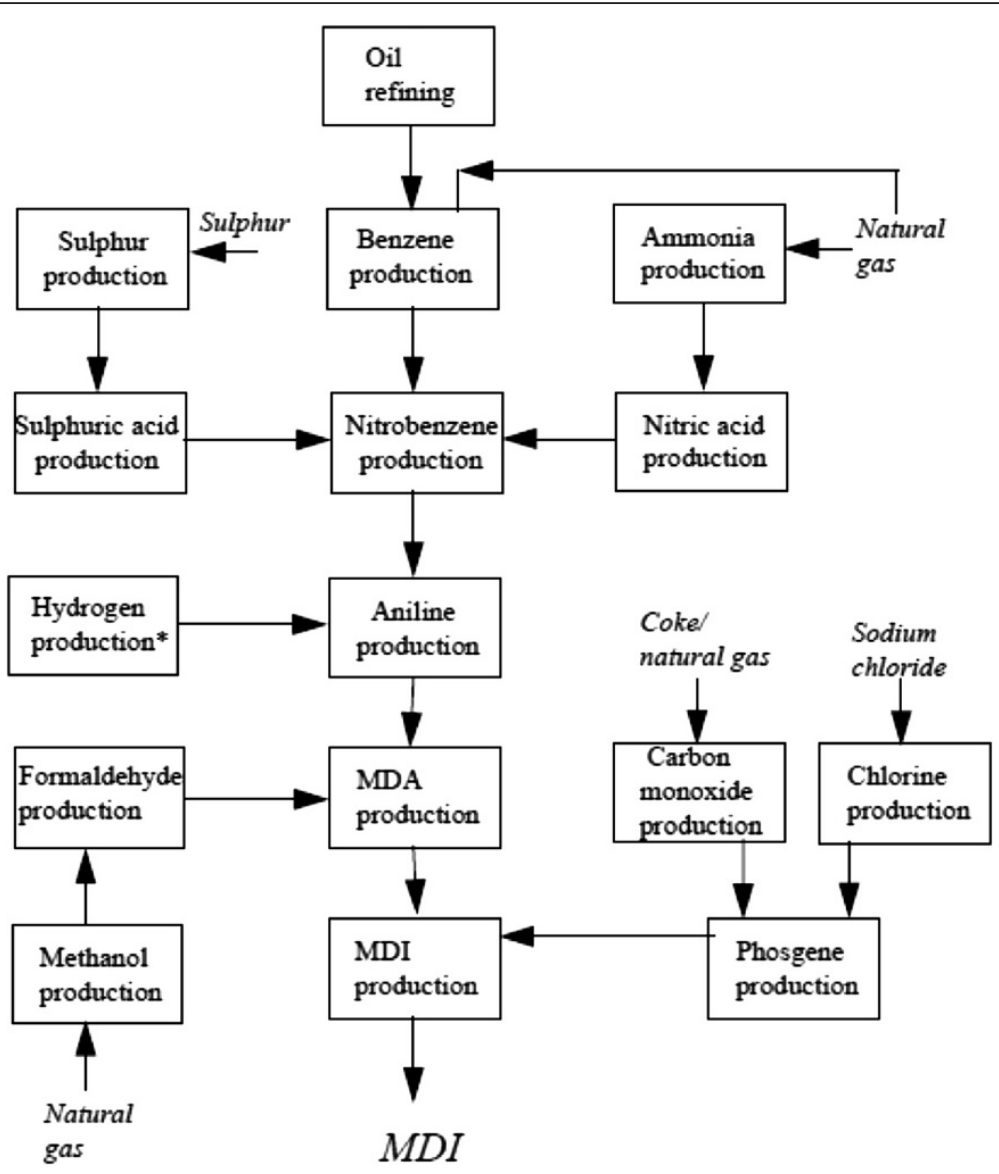

Figure 1 Schematic diagram showing the principal operations leading to the production of MDI. 
respiratory rate was 24 breaths per minute, and his body temperature was $36.8^{\circ} \mathrm{C}$. Although acutely ill, there was no sign of severe cyanoderma anywhere on his body. There were no findings of jaundice in the sclera or conjunctiva pallor according to a head and neck examination. Heart sounds were regular, with no abnormal murmurs. Respiratory sounds were also normal. There were no significant symptoms found in the abdominal region.

\section{Laboratory findings}

A peripheral blood examination revealed the following: hemoglobin level $15.3 \mathrm{~g} / \mathrm{dl}$, hematocrit $43.6 \%$, white blood cells $7,500 / \mathrm{mm}^{3}$, and platelet count $188,000 / \mathrm{mm}^{3}$. According to a biochemical examination, blood urea nitrogen (BUN) was $14.7 \mathrm{mg} / \mathrm{dL}$, creatinine was $1.0 \mathrm{mg} / \mathrm{dL}$, asparate aminotransferase (AST) was $19 \mathrm{IU} / \mathrm{L}$, and alanine aminotransferase (ALT) was $18 \mathrm{IU} / \mathrm{L}$. Urine test results were normal. An arterial blood gas examination revealed a $\mathrm{pH}$ of 7.41, $\mathrm{PCO}_{2}$ of $35.6 \mathrm{mmHg}, \mathrm{PO}_{2}$ of $161 \mathrm{mmHg}, \mathrm{HCO}_{3}{ }^{-}$of $21.9 \mathrm{mmol} / \mathrm{L}, \mathrm{O}_{2}$ saturation of $97.8 \%, \mathrm{O}_{2} \mathrm{Hb}$ (oxidized hemoglobin) of $78.6 \%$, and MetHb of $19.8 \%$.

\section{Electrocardiogram findings}

An electrocardiogram showed sinus rhythm, but the patient's heart rate was 60 beats per minute, which was a possible sign of sinus bradycardia.

\section{Medical imaging findings}

There were no significant findings on plain chest radiography and chest computed tomography.

\section{Clinical course}

The patient was diagnosed with methemoglobinemia according to the medical test results and his past exposure history to mononitrobenzene. As his MetHb levels were relatively low, he was given simple $\mathrm{O}_{2}$ inhalation treatment through a mask at $10 \mathrm{~L}$ per minute. Two hours after the treatment, his MetHb was reduced to $12.7 \%$, and his symptoms were alleviated. On his second day of hospitalization, his $\mathrm{pH}$ was 7.41, and $\mathrm{PCO}_{2}$ was $39.2 \mathrm{mmHg}, \mathrm{PO}_{2}$ was $86.3 \mathrm{mmHg}, \mathrm{HCO}_{3}{ }^{-}$was $24.5 \mathrm{mmol} / \mathrm{L}, \mathrm{O}_{2}$ saturation was $95.6 \%$, and MetHb was $2.1 \%$ according to an arterial blood gas examination (Table 1). The symptoms of methemoglobinemia, including dyspnea and cyanoderma, disappeared, and he was discharged from the hospital at $1 \mathrm{pm}$ on the same day.

\section{Case 2}

Patient

25-year-old male

\section{Chief complaint}

Signs of cyanoderma appeared one hour and thirty minutes after exposure to aniline.
Table 1 Progress of blood gas analysis and methemoglobin concentration of case 1

\begin{tabular}{lccc}
\hline & Initial & \multicolumn{2}{c}{ Progress $^{*}$} \\
\cline { 2 - 4 } & & 7.45 & 1 day later \\
\hline $\mathrm{pH}$ & 7.41 & 35.2 & 7.41 \\
$\mathrm{PCO}_{2}(\mathrm{mmHg})$ & 35.6 & 155 & 39.2 \\
$\mathrm{PO}_{2}(\mathrm{mmHg})$ & 161 & 24.3 & 86.3 \\
$\mathrm{HCO}_{3}^{-}(\mathrm{mmol} / \mathrm{L})$ & 21.9 & 98.1 & 24.5 \\
$\mathrm{O}_{2}$ saturation $\left.^{-} \%\right)$ & 97.8 & 12.7 & 95.6 \\
Methemoglobin (\%) & 19.8 & 2.1
\end{tabular}

*The patient was treated with $\mathrm{O}_{2}$ inhalation via mask $(10 \mathrm{~L} / \mathrm{min})$.

\section{Past medical history and/or family history}

Nothing significant.

\section{History of cigarette smoking and alcohol consumption}

Smoker of 2.5 pack-year, occasionally consumes alcohol

\section{Occupational history}

The patient works in the MDI production field and is in charge of loading and unloading aniline from bulk trucks. He was exposed to aniline while removing a connector from the tank of a lorry. Approximately $200 \mathrm{cc}$ of aniline that remained in the vent line spattered on his face and his upper body.

\section{History of present illness}

Following the exposure to the aniline, the patient was taken to a local hospital for emergency treatment and observation. He did not show any immediate symptoms other than pain caused by a burn around the exposed area. However, after $\mathrm{O}_{2}$ inhalation treatment $(5 \mathrm{~L} / \mathrm{min}$ via an $\mathrm{O}_{2}$ mask), he showed cyanoderma on his entire body, including his face. An arterial blood gas examination revealed $\mathrm{O}_{2}$ saturation was reduced from $91 \%$ to $89 \%$. The MetHb reading was $26.3 \%$. The patient was transferred to the emergency room after consulting the Department of Occupational \& Environmental Medicine of an affiliated university hospital in accordance with the emergency patient management guidelines of the workplace.

\section{Physical findings}

At the time of transfer, his blood pressure was 130/ $80 \mathrm{mmHg}$, his pulse rate was 80 beats per minute, his respiratory rate was 20 breaths per minute, and his body temperature was $36.0^{\circ} \mathrm{C}$. He was acutely ill and showed signs of cyanoderma on his entire body. A head and neck examination showed no findings of jaundice in the sclera or conjunctiva pallor. However, both eyelids showed signs of rubefaction (Figure 2). Heart sounds were regular, with no abnormal murmurs. Respiratory sounds were also normal, but the left side of his chest was red. There were no significant symptoms found in the abdominal region. Redness 


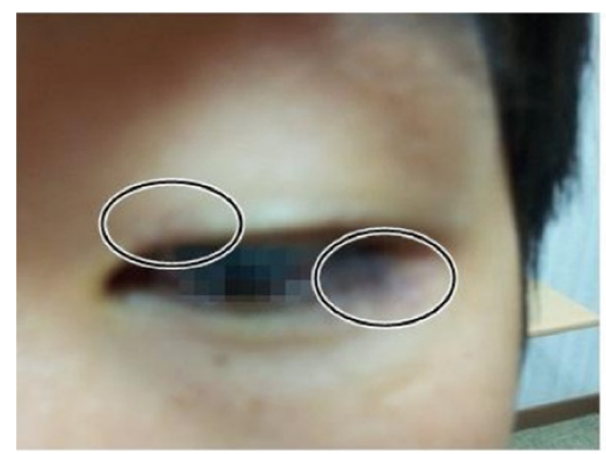

(A)

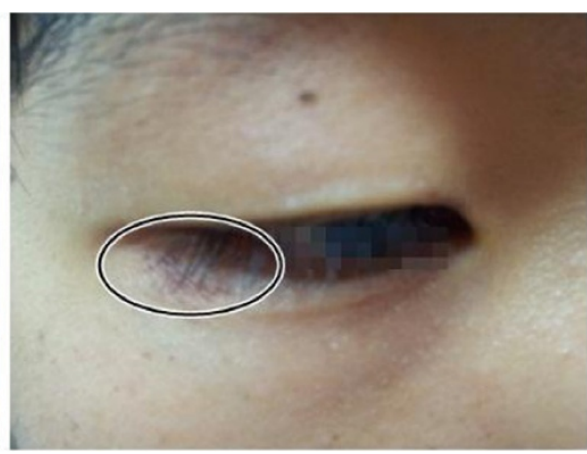

(B)

Figure 2 Skin irritation of upper and lower eyelids of both sides. (A) Left eyelids. (B) Right eyelids.

and blisters were observed in the concave area of both sides of his elbows (Figure 3).

\section{Laboratory findings}

A peripheral blood examination showed the following: hemoglobin level $14.4 \mathrm{~g} / \mathrm{dl}$, hematocrit $41.7 \%$, white blood cells $6,800 / \mathrm{mm}^{3}$, and platelet count $218,000 / \mathrm{mm}^{3}$. According to a biochemical examination, his BUN was $13.4 \mathrm{mg} / \mathrm{dL}$, creatinine was $0.6 \mathrm{mg} / \mathrm{dL}$, AST was $19 \mathrm{IU} / \mathrm{L}$, and ALT was $18 \mathrm{IU} / \mathrm{L}$. Urine test results were normal. According to the arterial blood gas examination, his $\mathrm{pH}$ was 7.41, $\mathrm{PCO}_{2}$ was $37.4 \mathrm{mmHg}, \mathrm{PO}_{2}$ was $185 \mathrm{mmHg}, \mathrm{HCO}_{3}{ }^{-}$was $23.0 \mathrm{mmol} / \mathrm{L}, \mathrm{O}_{2}$ saturation was $98.3 \%, \mathrm{O}_{2} \mathrm{Hb}$ (oxidized hemoglobin) was $51.9 \%$, and MetHb was $46.8 \%$.

\section{Electrocardiogram findings}

An electrocardiogram showed a sinus rhythm and a regular heart rate ( 65 beats per minute).

\section{Medical imaging findings}

There were no significant findings on plain chest radiography.

\section{Clinical course}

Based on the patient's medical test results, MetHb level, and exposure history to aniline, the patient was diagnosed with methemoglobinemia. $\mathrm{He}$ was given $\mathrm{O}_{2}$ inhalation treatment $(10 \mathrm{~L} / \mathrm{min}$ via a mask) and $7 \mathrm{ml}$ of $2 \%$ methylene blue diluted in $100 \mathrm{ml}$ of saline solution. His MetHb was $25.3 \%, 19.3 \%, 9.9 \%$, and $6.6 \%$ at one, two, four, and six hours, respectively after the treatment. According to an arterial blood gas examination on the second day of his hospitalization, his $\mathrm{pH}$ was $7.34, \mathrm{PCO}_{2}$ was $47.2 \mathrm{mmHg}$, $\mathrm{PO}_{2}$ was $237 \mathrm{mmHg}, \mathrm{HCO}_{3}{ }^{-}$was $25.0 \mathrm{mmol} / \mathrm{L}, \mathrm{O}_{2}$ saturation was $99.0 \%$, and MetHb was $2.4 \%$. The symptoms caused by the methemoglobinemia, such as cyanoderma, gradually improved. An ointment was applied to skin lesions (primary burns and contact dermatitis) caused by aniline. Eye drops were applied for cornea inflammation. According to an arterial blood gas examination on his fourth day of hospitalization, his $\mathrm{pH}$ was 7.46. $\mathrm{PCO}_{2}$ was $34.1 \mathrm{mmHg}, \mathrm{PO}_{2}$ was $119 \mathrm{mmHg}, \mathrm{HCO}_{3}{ }^{-}$was $24.2 \mathrm{mmol} / \mathrm{L}, \mathrm{O}_{2}$ saturation was $97.2 \%$, and MetHb was $0.8 \%$ (Table 2). The level of MetHb returned to normal. The symptoms of methemoglobinemia were gradually alleviated, and he was discharged from the hospital at $2 \mathrm{pm}$ on the seventh day of hospitalization.

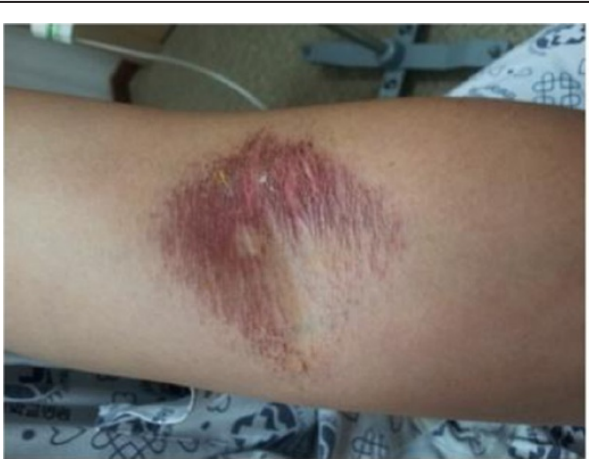

(A)

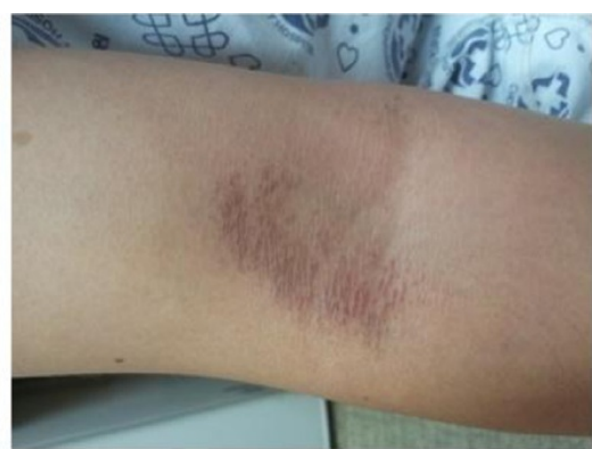

(B)

Figure 3 Skin lesions of antecubital fossa of both arms. (A) Left antecubital fossa. (B) Right antecubital fossa. 
Table 2 Progress of blood gas analysis and methemoglobin concentration of case 2

\begin{tabular}{ccccccccc}
\hline & Initial $^{*}$ & \multicolumn{7}{c}{ Progress $^{\dagger}$} \\
\cline { 3 - 8 } & & 1 hour later & 2 hours later & 4 hours later & 6 hours later & 1 day later & 2 days later & 3 days later \\
\hline $\mathrm{pH}$ & 7.41 & 7.40 & 7.40 & 7.36 & 7.34 & 7.34 & 7.42 & 7.46 \\
$\mathrm{PCO}_{2}(\mathrm{mmHg})$ & 37.4 & 41.3 & 38.1 & 43.5 & 45.0 & 47.2 & 39.1 & 34.1 \\
$\mathrm{PO}_{2}(\mathrm{mmHg})$ & 185 & 221 & 200.9 & 261.1 & 345 & 237 & 114 & 119 \\
$\mathrm{HCO}_{3}^{-}$(mmol/L) & 23.0 & 23.5 & 23.1 & 24.2 & 23.6 & 25.0 & 25.0 & 24.2 \\
$\mathrm{O}_{2}$ saturation (\%) & 98.3 & 98.5 & 98.6 & 99.0 & 99.2 & 99.0 & 98.3 & 97.2 \\
Methemoglobin (\%) & 46.8 & 25.3 & 19.3 & 9.9 & 6.6 & 2.4 & 1.5 & 0.8 \\
\hline
\end{tabular}

*The MetHb at the local hospital was $26.3 \%$.

${ }^{\dagger}$ The patient was initially treated with injection of $2 \%$ methylene blue and $\mathrm{O}_{2}$ inhalation.

\section{Conclusions}

As mentioned above, the majority of acquired methemoglobinemia occurs through nonoccupational exposure. Several cases of occupational exposure have been reported during repair and maintenance in production of aniline, medical substances, pesticides, and rubber. Occupational exposure has also occurred during transportation and disposal of substances that cause methemoglobinemia $[1,5]$. In addition to being uncommon, such exposure is rarely fatal.

Hemoglobin is oxidized into MetHb via three main mechanisms, depending on the source of exposure. Direct oxidization of hemoglobin occurs in response to exposure to specific substances, such as copper (II) sulfate and hexavalent chromates. It relies on the redox potential of the substance relative to hemoglobin. Indirect oxidation of hemoglobin, for example, by nitrites and phenylenediamine, relies on a co-oxidation mechanism. Lastly, there are cases where the substance itself is not sufficient to create MetHb. In such cases, MetHb is created following exposure to specific metabolic activities in the body and subsequent biochemical changes. The occupational exposure cases reported herein where the workers were exposed to aniline and nitrobenzene fall into this category [1].

Occupational exposure to nitrobenzene occurs via inhalation and absorption through the skin. Once it is absorbed, nitrobenzene is metabolized into nitrosobenzene, which is toxic and causes methemoglobinemia $[1,14,20]$. According to international and domestic studies on nitrobenzene addiction, most exposure takes place via ingestion and absorption through the skin [13-15,21-23].

In the first case, the worker developed symptoms after cleaning a suction strainer of a mononitrobenzene pump for six or seven hours, but he showed no signs of exposure through ingestion or absorption through the skin. The time-weighted average (TWA) of nitrobenzene exposure regulation in Korea is $1 \mathrm{ppm}$. Markers of nitrobenzene exposure include urinary p-nitrophenol and the aniline concentration level in the blood, but these are nonspecific markers $[14,20,24]$. One limitation of the current study was the absence of a direct evaluation of the work environment. However, because the worker had no prior drug history or exposure to other chemicals that could have caused methemoglobinemia, his exposure to nitrobenzene during the work process was clear. In addition, as $\mathrm{MetHb}$ is often used as a biomarker of nitrobenzene exposure, his methemoglobinemia was diagnosed to be caused by exposure to nitrobenzene.

It is known that occupational exposure to aniline can occur via inhalation through respiratory organs, oral ingestion, and absorption through the skin and that aniline causes methemoglobinemia following oxidation via phenyl hydroxylamine, a metabolite [1,14,17-19]. According to prior cases of aniline exposure, the majority of cases involved oral ingestion and inhalation through the respiratory organs [17-19].

In the second case, the worker was removing a connector from the tank of an aniline lorry when approximately $200 \mathrm{cc}$ of aniline remaining in the vent line spattered on his face and his upper body. Although the possibility of inhalation cannot be ignored, it can be assumed that the major exposure to aniline was absorption through the skin. The TWA of aniline exposure regulation in Korea is 2 ppm, and urinary p-aminophenol is used as a biomarker [19,24]. The worker in this case had no prior intake history of drugs that may have caused the methemoglobinemia, and his methemoglobinemia was diagnosed as due to exposure to aniline.

The diagnosis of methemoglobinemia is based on the results of an arterial blood gas examination and measurements of the concentration of MetHb in the blood [1]. The symptoms of methemoglobinemia differ depending on the concentration level of MetHb in the blood, with 0 $20 \%$ potentially producing cyanoderma; $20-40 \%$ potentially producing headache, anxiety, vertigo, and a frequent pulse; $40-60 \%$ potentially producing clouding of consciousness and respiratory failure; and more than $60 \%$ potentially resulting in arrhythmia, convulsion, and even death $[1,5]$.

Discontinued exposure to the substance, oxygen therapy, and intravenous injection of methylene blue are some of the options for methemoglobinemia [1,5,25-27]. Under 
normal circumstances, humans have less than $1 \%$ of MetHb in their bodies. In that case, hemoglobin convert to MetHb and MetHb revert to hemoglobin interactively. $\mathrm{MetHb}$ may revert to hemoglobin via a reaction involving nicotinamide dinucleotide hydrogenase (NADH) and nicotinamide-adenine dinucleotide phosphate hydrogenase (NADPH). In living tissue, most MetHb is reduced through NADH-dependent reactions rather than via NADPH-dependent reactions. Methylene blue combats methemoglobinemia by activating NADPH reactions and accelerating the reduction process of MetHb [1,4,5]. Methylene blue treatment is applicable when a patient's MetHb exceeds $25-30 \%$ or when the patient exhibits symptoms of oxygen deficiency, such as dyspnea and alteration of consciousness [1,22].

In the first of the presented cases, oxygen treatment alone improved the patient's symptoms and led to a decrease in his MetHb because his initial MetHb level was $19.8 \%$. In the second case, methylene blue treatment was required because the patient's MetHb level was 46.8\%, and his symptoms improved after the treatment.

The final clinical progress of both workers was positive. According to other reports of occupational exposure to substances that cause methemoglobinemia, fatal outcomes are rare [1]. However, methemoglobinemia is caused by various substances. If specific exposure paths are not diagnosed and understood, early stages of treatment may not be sufficient or appropriate. In extreme cases, this could lead to death. The worker in Case 2 showed no fatal symptoms in the beginning but developed cyanoderma and increased MetHb levels close to $50 \%$ as time passed. This case highlights the need for all workers who handle methemoglobinemia-causing substances to be provided with access to a medical institution with plenty of experience in occupational and environmental medicine.

Ultimately, methemoglobinemia-causing substances, such as nitrobenzene and aniline, can be absorbed by workers at petrochemical plants in various ways, and symptoms may not appear for a few hours after exposure. Businesses that handle such substances must have a strict maintenance system in place, as well as a protection system for workers, including regular exposure check-ups and an emergency patient management system to ensure that all workers have access to timely diagnosis and treatment at an affiliated medical institution.

\section{Consent}

Written informed consent was obtained from the patient's guardian/parent/next of kin for the publication of this report and any accompanying images.

\section{Competing interests}

We have no competing interests.

\section{Authors' contributions}

LCH and MJD conceived the study. CYH were involved in patient management. $\mathrm{KSH}$ and $\mathrm{KDH}$ collected medical and occupational information. LCH wrote the manuscript. JKH and MJD performed interpretation of the data and reviewed the manuscript. All authors read and approved the final manuscript.

\section{Author details}

${ }^{1}$ Department of Occupational and Environmental Medicine, Chonnam National University Hwasun Hospital, Hwasun, Korea. ${ }^{2}$ Department of Emergency Medicine, Chonnam National University Hospital, Gwangju, Korea.

Received: 27 September 2013 Accepted: 18 October 2013

Published: 1 November 2013

\section{References}

1. Bradberry SM, Aw TC, Williams NR, Vale JA: Occupational methemoglobinaemia. Occup Environ Med 2001, 58(9):611-616.

2. Park SS, Nam EM, Kim IH, Kim JS, Lim YJ, Ahn SJ: A case of methemoglobinemia caused by hair dyeing with henna. Korean J Med 2007, 72(2):314-317.

3. Shin JH, Lee JK, Park SS, Na SJ, Park JS: Indoxacarb pesticide poisoning with methemoglobinemia. J Korean Soc Clin Toxicol 2006, 4(2):158-160.

4. Kunos CA, Radivoyevitch T, Ingalls ST, Hoppel CL: Management of 3-aminopyridine-2-carboxaldehyde thiosemicarbazone-induced methemoglobinemia. Future Oncol 2012, 8(2):145-150.

5. Al-Lawati A, Murch N: Acquired methemoglobinaemia. SQU Med J 2012, 12(2):237-241.

6. Lee MJ, Park KN: A case of acute dapsone poisoning complicated with methyelene blue-induced hemolytic anemia. J Korean Soc Clin Toxicol 2006, 4(2):170-174.

7. Sharma VK, Haber AD: Acquired methemoglobinemia: a case report of benzocaine-induced methemoglobinemia and a review of the literature. Clin Pul M 2002, 9(1):53-58.

8. Tantisattamo E, Suwantarat N, Vierra JR, Evans SJ: Atypical presentations of methemoglobinemia from benzocaine spray. Hawaii Med J 2011, 70(6):125-126.

9. Weichert I: Acute management of cocaine-associated methaemoglobinaemia. Case Rep Med 2011, 2011:136396.

10. Canning J, Levine M: Case files of the medical toxicology fellowship at Banner Good Samaritan Medical Center in Phoenix, AZ: methemoglobinemia following dapsone exposure. J Med Toxicol 2011, 7:139-146.

11. Kim SP, Kim DH, Sun KH, Yoon DH, Kim SJ, Cho SH, Cho NS: A patient with methemoglobinemia after herbicide intoxication has hemolytic anemia induced by methylene blue. J Korean Soc Clin Toxicol 2008, 6(2):134-137.

12. NTP: Nitrobenzene. Rep Carcinog 2011, 12:294-6.

13. Min JW, Park SY, Lee GR, Jeon YD, Jung JY, Cho YJ, Nam HW: Case of acute methemoglobinemia caused by nitrobenzene ingestion. Korean J Med 2013, 84(3):442-445.

14. Martinez MA, Ballesteros S, Almarza E, Sanchez de la Torre C, Bua S: Acute nitrobenzene poisoning with severe associated methemoglobinmeia: identification in whole blood by GF-FID and GC-MS. J Anal Toxicol 2003, 27(4):221-5.

15. Saxena $H$, Saxena AP: Acute methemoglobinmeia due to ingestion of nirobenzene(paint solvent). Indian J Anaesth 2010, 54(2):160-2.

16. Aniline fact sheet. http://www.epa.gov/chemfact/anali-fs.pdf.

17. Kearney TE, Manoguerra AS, Dunford JV: Chemically induced methemoglobinemia from aniline poisoning. West J Med 1984, 140(2):282-6.

18. CDC: Severe methemoglobinemia and hemolytic anemia from aniline purchased as 2C-E (4-ethyl-2,5-dimethoxyphenethylamine), a recreational drug, on the internet - Oregon, 2011. Morb Mortal Wkly Rep 2012, 61(5):85-8.

19. Pizon AF, Schwartz AR, Shum LM, Rittenberger JC, Lower DR, Giannoutsos S, Virji MA, Krasowski MD: Toxicology laboratory analysis and human exposure to p-chloroaniline. Clin Toxicol 2009, 47(2):132-136.

20. Toxicological review of nitrobenzene. http://www.epa.gov/iris/toxreviews/ 0079tr.pdf.

21. Hishima MD, Vijayakumar A, Rajesh N, Sivakumar MN: Acute nitrobenzene poisoning with severe methemoglobinemia: a case report. Indian J Pharm Pract 2012, 5(4):84-86. 
22. Chongtham DS, Phurailatpam J, Singh MM, Singh TR: Methaemoglobinemia in nitrobenzene poisoning. J Postgrad Med 1997, 43(3):73-4.

23. Singh R, Vinayagam S, Vajifdar $\mathrm{H}$ : Methemoglobinemia as a result of accidental lacquer thinner poisoning. Indian J Crit Care Med 2012, 16(1):44-47

24. The exposure limits of chemical and physical hazards (translated by Lee CH). http://www.moel.go.kr/view.jsp?cate $=3 \&$ sec $=1 \&$ smenu=4.

25. Tejesh CA, Shivanna S, Manjunath AC, Prathima PT: ICU management of methemoglobinemia due to unknown compound poisoning. J Anaesthesiol Clin Pharmacol 2013, 29(1):139-140.

26. Su YF, Lu LH, Hsu TH, Chang SL, Lin RT: Successful treatment of methemoglobinemia in an elderly couple with severe cyanosis: two case reports. J Med Case Rep 2012, 6(1):290.

27. Shim JY, Seo YS, Gil HW, Yang JO, Lee EY, Hong SY: A fatal case of methylene blue treatment failure in methemoglobinemia. J Korean Soc Clin Toxicol 2006, 4(2):151-154.

doi:10.1186/2052-4374-25-31

Cite this article as: Lee et al.: Two Cases of Methemoglobinemia Induced by the Exposure to Nitrobenzene and Aniline. Annals of Occupational and Environmental Medicine 2013 25:31.

\section{Submit your next manuscript to BioMed Central and take full advantage of:}

- Convenient online submission

- Thorough peer review

- No space constraints or color figure charges

- Immediate publication on acceptance

- Inclusion in PubMed, CAS, Scopus and Google Scholar

- Research which is freely available for redistribution 